\title{
The Impact of MTHFR 1298 A > C and 677 C > T Gene Polymorphisms as Susceptibility Risk Factors in Cervical Intraepithelial Neoplasia Related to HPV and Sexually Transmitted Infections
}

\author{
Amir Sohrabi ${ }^{1}$ D $\cdot$ Fatemeh Bassam-Tolami ${ }^{2} \cdot$ Mohsen Imani $^{3}$
}

Received: 28 February 2020 / Accepted: 25 July 2020 / Published online: 24 August 2020

(c) The Author(s) 2020

\begin{abstract}
Background HPV genotypes are the most common etiological factor for genital neoplasia. It would appear that sexually transmitted infections accompanied with HPV genotypes might have synergistic interactions in cancer progression. The genetic polymorphisms are involved in metabolizing carcinogens which may contribute to the susceptibility of developing genital cancers by less efficient or overly down metabolic pathways and cell signaling. MTHFR polymorphisms are related to several metabolic disorders and human cancers. We investigated the contribution of MTHFR 1298 and MTHFR 677 polymorphisms as potential risk factors for outcomes with HPV genotypes and STIs in Iranian population.

Materials and Methods As a case-control study, MTHFR A1298C and C677T were assessed for SNPs analysis using a PCR-RFLP assay in 50 cervical intraepithelial neoplasia (CIN) cases, 98 HPV-positive subjects and 47 non-cancerous/ non-HPV patients as healthy controls.

Results Finding suggested a significant association between the MTHFR $1298 \mathrm{CC}$ polymorphisms $(\mathrm{OR}=3.5,95 \% \mathrm{CI}=1.13-$ $10.82, P \leq 0.05)$ in women with CIN as compared to non-cancerous/non-HPV subjects. There was not a significant difference of MTHFR 677 between outcomes.

Discussion It would seem MTHFR $1298 \mathrm{CC}$ is more likely to be a potential risk factor for HPV-cervical cancer progression. Consequences support further attempts to understand the clinical manifestations of neoplasia related to genital infections and gene mutations.
\end{abstract}

Keywords HPV · STI · Genital infection · Cervical cancer · MTHFR · Polymorphism

Amir Sohrabi, PhD, in Molecular Medicine, Department of Medical Epidemiology and Biostatistics, Karolinska Institutet, Stockholm, Sweden. Fatemeh Bassam-Tolami, MSc, in Biochemistry, Department of Biology, Tehran Shargh Branch, Payame Noor University, Tehran, Iran. Mohsen Imani, MSc, in Immunology, Department of Molecular Biology, Research Center of Health Reference Laboratory, Ministry of Health and Medical Education, Tehran, Iran.

Amir Sohrabi

amir.sohrabi@ki.se; sohrabi58@gmail.com

1 Department of Medical Epidemiology and Biostatistics, Karolinska Institutet, Nobels väg 12A, Solna Campus, PO Box 171 77, Stockholm, Sweden

2 Department of Biology, Tehran Shargh Branch, Payame Noor University, Tehran, Iran

3 Department of Molecular Biology, Research Center of Health Reference Laboratory, Ministry of Health and Medical Education, Tehran, Iran

\section{Introduction}

Cervical malignancies are one of the most common disorders in females worldwide. Approximately 86 percent of these cases occur in developing communities, where careHPV, prophylactic screening and a nationally organized program are not commonly available. Lifestyle, environmental conditions, coinfections, genetic patterns and epigenetic characteristics accompanied with HPV genotypes are major risk factors for genital malignancies and disorders [1-3].

Most sexually active women and men are infected at some points in their lives. Additional microbial pathogens such as sexually transmitted infections (STIs) could increase the risk of cervical neoplasia induction [1]. Some single-nucleotide polymorphisms (SNPs) and STI, especially HPV infections, are considered predisposing factors for genital cancerous lesion progression $[4,5]$. 
Methylenetetrahydrofolate reductase, folate-metabolizing enzyme, is a critical component in complex process of folate cycle. SNPs in the MTHFR gene are arguably associated with thrombotic events and may increase or decrease the activity of cancer suppressor genes. Homozygosity for the substitution $(\mathrm{C} \rightarrow \mathrm{T})$ at nucleotide 677 and for the substitution $(\mathrm{A} \rightarrow \mathrm{C})$ at nucleotide 1298 in the MTHFR gene is suggested to be associated with an increased risk of cervical cancer [6-10].

Few studies are found on the association between polymorphisms and STIs related to cervical cancer. The need for identifying genetic susceptibility factors for $\mathrm{CC}$ related to HPV and STI is a matter of debate [11]. Therefore, the present study was designed to evaluate the C677T and A1298C mutations of MTHFR gene in cervical intraepithelial neoplasia (CIN) related to HPVs subjects and most common sexually transmitted pathogens such as Chlamydia trachomatis, HSV-2 and Mycoplasma genitalium in Iranian women suffering from STI coinfections.

\section{Materials and Methods}

\section{Patients' Specimens}

In this case-control study, 148 women who were referred to Moheb Yas Hospital and other private laboratories in Tehran, Iran with or without genital infections and cervical intraepithelial neoplasia were enrolled in the survey. Fortyseven age- and sex-matched healthy controls were consecutively registered for this study from April 2012 to October 2015. Informed consent was obtained from subjects prior to their registration. Cervical scrapping and genital lesions with known cervical intraepithelial neoplasia (all the diagnoses were confirmed by histopathological examinations), HPV-positive subjects and non-cancerous/non-HPV women as healthy controls were 50, 98 and 47, respectively. These liquid-based cytology samples (LBCs) were transported to a molecular biology laboratory where they were stored in proper condition until genomic analysis.

\section{DNA Extraction}

Extraction of infectious agents and genomic DNAs from LBCs and lesions was performed using a high pure PCR template preparation kit (Roche $\odot$, Germany), following the kit protocol. Extracted DNAs were kept at $-20{ }^{\circ} \mathrm{C}$ until experiment.

\section{PCR-RFLP Analysis of MTHFR}

Briefly, a 25- $\mu$ l reaction mixture containing 2x Master Mix PCR (Amplicon ${ }^{\circledR}$, Denmark), $10 \mathrm{pmol} / \mu \mathrm{l}$ of forward and reverse specific primers and $10 \mu 1$ of the extracted DNA as a template in separate reactions was used for evaluation of MTHFR1298 and 677 mutations. The reactions were amplified in a thermal cycler (PeQlab $\left.{ }^{\circledR}, \mathrm{UK}\right)$ by using the following conditions: primary denaturation of $94^{\circ} \mathrm{C}$ for 5 min, 32 cycles with $94{ }^{\circ} \mathrm{C}$ for $1 \mathrm{~min}, 63^{\circ} \mathrm{C}$ for $1 \mathrm{~min}$ and $72{ }^{\circ} \mathrm{C}$ for $1 \mathrm{~min}$, plus an additional extension at $72{ }^{\circ} \mathrm{C}$ for $10 \mathrm{~min}$. In RFLP analysis, $15 \mu \mathrm{l}$ of $1298 \mathrm{~A}>\mathrm{C}$ PCR products were digested with $20 \mu$ of restriction enzyme reaction mixture containing $16 \mu \mathrm{l}$ of sterile distilled water, 3 of $\mu \mathrm{l}$ blue buffer and $1 \mu \mathrm{l}$ of MboII ( $5 \mathrm{U} / \mu \mathrm{L})$ enzyme (Thermo Scientific ${ }^{\circledR}$ ). In addition, $10 \mu 1$ of $677 \mathrm{C}>\mathrm{T}$ PCR products were digested with $20 \mu \mathrm{l}$ of restriction enzyme mixture containing $16 \mu \mathrm{l}$ of sterile distilled water, $3 \mu \mathrm{l}$ of Tango buffer and $1 \mu \mathrm{l}$ of HinfI enzyme $(10 \mathrm{U} / \mu \mathrm{L}$ ) (Thermo Scientific ${ }^{\circledR}$ ). The PCR-RFLP products were separated by electrophoresis on a $3 \%$ agarose gel, stained by SYBR Safe, and were visualized under ultraviolet light along with a molecular weight marker (50 bp). In a MTHFR 1298, PCR-RFLP was expected to produce 145 bp as undigested, 77, 37 and $29 \mathrm{bp}$ as wild type, 108, 77, 37 and $29 \mathrm{bp}$ as heterozygous and $108 \mathrm{bp}$ as homozygous. In addition, in a MTHFR 677 PCR-RFLP was expected to produce $200 \mathrm{bp}$ as undigested, $200 \mathrm{bp}$ as wild type, 200 and $175 \mathrm{bp}$ as heterozygous and $175 \mathrm{bp}$ as homozygous $[12,13]$.

\section{Sexually Transmitted Pathogens Detection}

HPV genotyping was performed by a reverse dot blot hybridization diagnostic kit using INNO-LiPA ${ }^{\circledR}$ HPV Genotyping Extra I (Innogenetics $\odot$ )/INNO-LiPA ${ }^{\circledR}$ HPV Genotyping Extra II (Fujirebio (O), according to the previously described method. HSV-2, M. genitalium and $C$. trachomatis as STIs infections were diagnosed by multiplex quantitative TaqMan real-time PCR which was optimized in our previous study $[14,15]$.

\section{Statistical Analysis}

The SPSS statistics 23.0 was applied for data analysis. The crude and adjusted odds ratio (OR) and 95\% confidence intervals $(\mathrm{CI})$ were calculated with binary logistic regression. In addition, Pearson's Chi-square test was used for comparing relationship between MTHFR $1298 \mathrm{~A}>\mathrm{C}$ and $677 \mathrm{C}>\mathrm{T}$ genotypes and pathological staging of cervical cancer. $P$ value of $<0.05$ was considered as significant. Allele frequencies of 1298 and 677 mutations were calculated using Hardy-Weinberg equilibrium. The $\chi^{2}$ test was employed to study the deviation from Hardy-Weinberg equilibrium between the observed and expected genotype frequencies in controls. 


\section{Results}

The mean age of 148 women with HPV infection and cervical cancer was $37.84 \pm 10.55$ years, and it was $36.62 \pm 9.63$ years for 47 healthy controls (non-cancerous/ non-HPV) who were recruited in the current case-control study.

We performed a detailed HPV genotyping and pathogen detection of STIs such as $C$. trachomatis, HSV2 and $M$. genitalium in our previous studies [13, 14]. The details of data are not shown. Subjects infected with high-risk HPV genotypes were at higher risk of cervical cancer $(P \leq 0.05)$. The distribution for the MTHFR A1298C and C677T genotypes in different subjects is shown in Table 1 and Fig. 1. The frequencies of the MTHFR C677T CC, CT and TT genotypes were 52.3, 43.6 and $4.1 \%$ among control patients and 48, 52 and $0 \%$ among cervical intraepithelial neoplasia cases, respectively. The frequencies of the MTHFR A1298C AA, AC and CC genotypes were $38.9,41$ and $20 \%$ among population study and 34,32 and $34 \%$ among cervical intraepithelial neoplasia group, respectively. No significant evidence was found for STI pathogens and these polymorphisms $(P$ value $\geq 0.05)$. The details of MTHFR genotypes prevalence in women with STI pathogens are shown in Table 2. The MTHFR A1298C and C677T genotype frequencies of HPV non-cancerous/ non-HPV group were in Hardy-Weinberg equilibrium. [Chi-square was $0.129,0.21$ and 1.43 ( $P$ value $\geq 0.05)$.] Comparison of the MTHFR 1298 and 677 polymorphisms between each of the cervical intraepithelial neoplasia subjects, HPV-infected cases and non-cancer/non-HPVs control indicated a significant difference in some genotypes. There was a significant association between the MTHFR 1298 CC polymorphisms (adjusted OR $=3.5$, $95 \% \mathrm{CI}=1.13-10.82, P \leq 0.05)$ in women with cervical intraepithelial neoplasia and non-cancerous/non-HPV control group.

There was no significant difference between MTHFR 677 genotypes and population study. The heterogeneity, odds ratios and Hardy-Weinberg results are shown in Table 3.

\section{Discussion}

The association between the MTHFR $1298 \mathrm{~A}>\mathrm{C}$ and 677 $\mathrm{C}>\mathrm{T}$ polymorphisms and susceptibility to cervical malignancies and genital disorders has been investigated in the

Table 1 The distribution of MTHFR A1298C and C677T genotypes in study population

\begin{tabular}{|c|c|c|c|c|c|c|c|}
\hline \multirow[t]{2}{*}{ Clinical subjects } & & \multicolumn{3}{|c|}{ MTHFR $1298 \mathrm{~A}>\mathrm{C}$} & \multicolumn{3}{|c|}{ MTHFR $677 \mathrm{C}>\mathrm{T}$} \\
\hline & & Wild type & Heterozygous & Homozygous & Wild type & Heterozygous & Homozygous \\
\hline \multirow{2}{*}{$\begin{array}{l}\text { Women without } \\
\text { cervical intraepi- } \\
\text { thelial neoplasia } \\
\text { (145 cases) }\end{array}$} & HPV positive (98 cases) & $38(38.7 \%)$ & $44(44 \%)$ & $16(16.3 \%)$ & $51(52.02 \%)$ & $41(41.83 \%)$ & $6(6.12 \%)$ \\
\hline & $\begin{array}{l}\text { Non-HPV/non-cancerous ( } 47 \\
\text { cases) }\end{array}$ & $21(44.7 \%)$ & $20(42.55 \%)$ & $6(12.75 \%)$ & $27(57.4 \%)$ & $18(38.3 \%)$ & $2(4.3 \%)$ \\
\hline $\begin{array}{l}\text { Women with cervi- } \\
\text { cal intraepithelial } \\
\text { neoplasia ( } 50 \\
\text { cases) }\end{array}$ & $\begin{array}{l}\text { CIN I }=9 \text { cases, } \text { CIN II }=6 \text { cases, } \\
\text { CIN III }=35 \text { cases }\end{array}$ & $17(34 \%)$ & $16(32 \%)$ & $17(34 \%)$ & $24(48 \%)$ & $26(52 \%)$ & $0 \%$ \\
\hline Total & & $76(38.9 \%)$ & $80(41 \%)$ & $39(20 \%)$ & $102(52.3 \%)$ & $85(43.6 \%)$ & $8(4.1 \%)$ \\
\hline
\end{tabular}

Fig. 1 Frequency of MTHFR 1298 and MTHFR 677 genotypes in cervical intraepithelial neoplasia (CIN) subjects

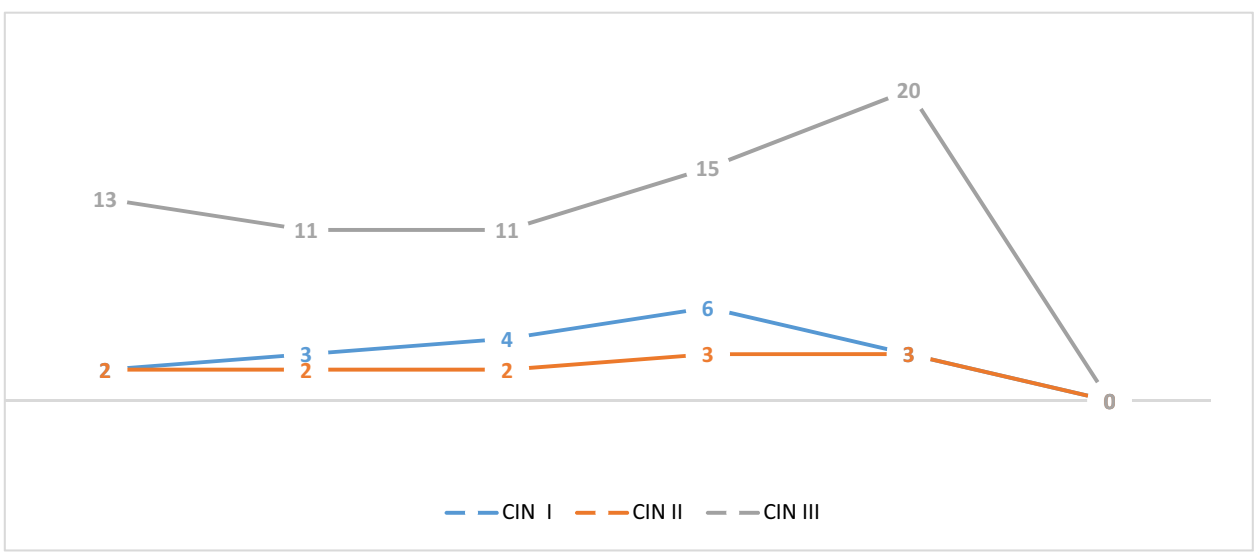




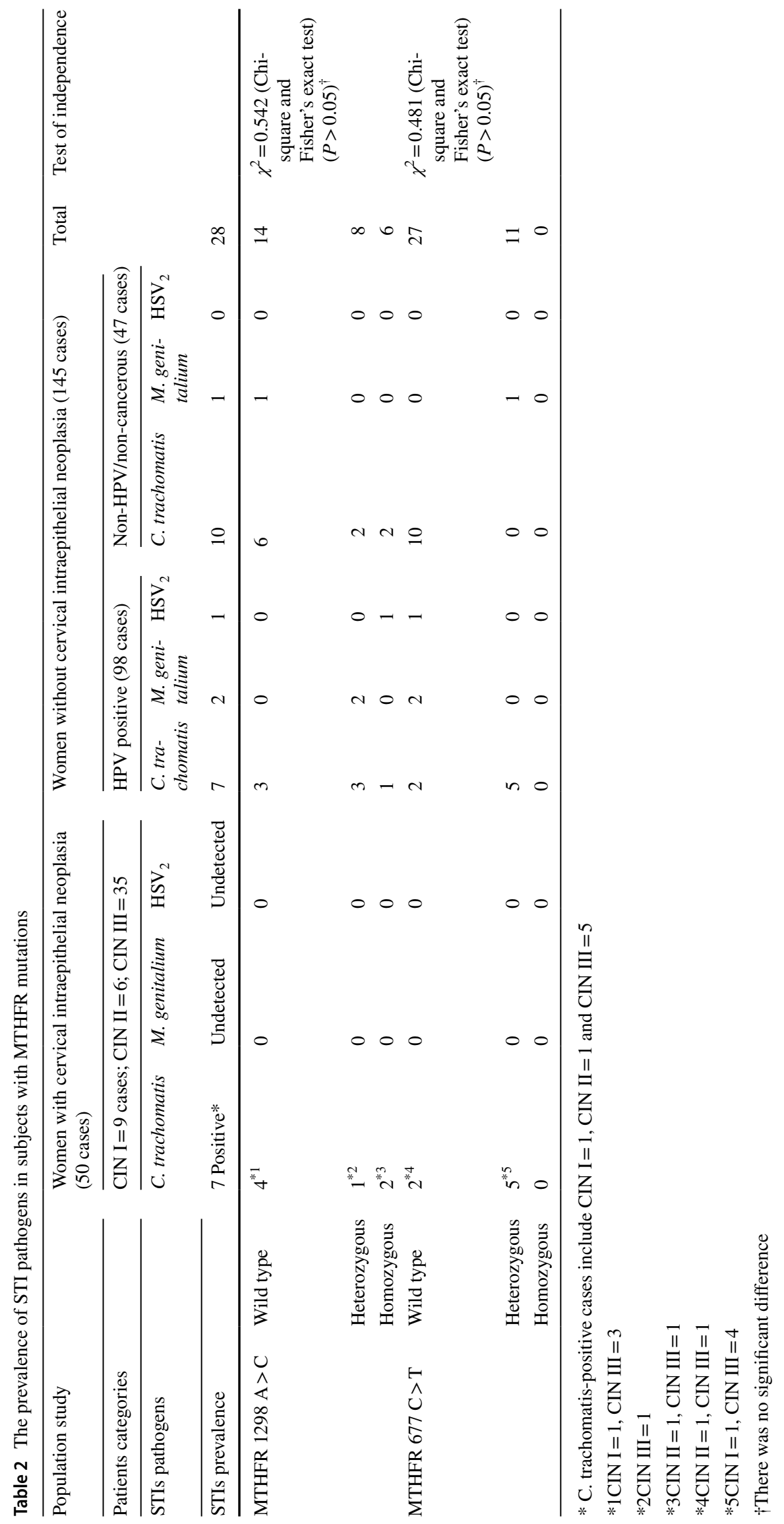


Table 3 Heterogeneity, odds ratios and Hardy-Weinberg results in the association between MTHFR polymorphisms and cervical intraepithelial neoplasia

\begin{tabular}{|c|c|c|c|c|c|c|c|c|}
\hline \multirow[t]{2}{*}{ Genotype } & \multirow{2}{*}{$\begin{array}{l}\text { Cervical intraepithelial } \\
\text { neoplasia } n=50\end{array}$} & \multirow{2}{*}{$\begin{array}{l}\text { HPV-positive } \\
\text { patients } n=98\end{array}$} & \multirow{2}{*}{$\begin{array}{l}\text { Non-HPV/non- } \\
\text { cancerous } n=47\end{array}$} & \multirow[t]{2}{*}{ OR } & \multirow[t]{2}{*}{$95 \% \mathrm{CI}$} & \multirow[t]{2}{*}{$P$ value } & \multicolumn{2}{|c|}{$\mathrm{HWE}_{\text {(control) }}$} \\
\hline & & & & & & & $\overline{\chi^{2}}$ & $P$ value \\
\hline \multicolumn{9}{|c|}{ MTHFR $1298 A>C$} \\
\hline $\mathrm{AA}$ & $17(34 \%)$ & $38(38.7 \%)$ & $21(44.7 \%)$ & 1.00 & Reference & & 0.129 & 0.71 \\
\hline $\mathrm{AC}$ & $16(32 \%)$ & $44(44 \%)$ & $20(42.55 \%)$ & 0.99 & $0.39-2.47$ & 0.99 & & \\
\hline $\mathrm{CC}$ & $17(34 \%)$ & $16(16.3 \%)$ & $6(12.75 \%)$ & 3.5 & $1.13-10.82$ & $0.03^{\dagger}$ & & \\
\hline \multicolumn{9}{|c|}{ MTHFR $677 C>T$} \\
\hline $\mathrm{CC}$ & $24(48 \%)$ & $51(52.02 \%)$ & $27(57.4 \%)$ & 1.00 & Reference & & 0.21 & 0.64 \\
\hline CT & $26(52 \%)$ & $41(41.83 \%)$ & $18(38.3 \%)$ & 1.62 & $0.72-3.67$ & 0.24 & & \\
\hline TT & 0 & $6(6.12 \%)$ & $2(4.3 \%)$ & 0.00 & 0.00 & 0.99 & & \\
\hline
\end{tabular}

${ }^{\dagger} P$ value $\leq 0.05$ (significant)

case-control study in Iranian women. We found that HPV 6 (LR), HPV 16 (HR) and C. trachomatis were the most common infections among the cervical intraepithelial neoplasia patients and healthy controls. However, HPV 6 is the most common genital infection that might not be an etiological factor for cervical cancer, but is a major cause of genital warts. It seems no previous study has reported the MTHFR A1298C and MTHFR C677T mutations in cervical cancer and STIs pathogens in Iranian women and west Asian regions. Extensive evidence propose that methylenetetrahydrofolate reductase (MTHFR) includes MTHFR A1298C and MTHFR C677T genotypes which may be implicated as potential risk factors in developing cervical cancer. It would appear that gene polymorphisms are implicated in cancer progression and they can be used for screening early stage of malignancies [16-19]. As a result, some genital infections such as high-risk HPVs and STIs are the common causative pathogens of cervical cancer and genital disorders. In addition, multiple co-pathogens appear more likely to be linked and potential risk factors in development of cervical abnormalities, especially in patients with genital infections [14, 20-24].

The function of SNPs in the pathogenesis of cervical cancer coexisting with HPV genotypes and other microorganisms such as $C$. trachomatis, M. genitalium and HSV2 in genital disorders has not been extensively studied in developing countries. Multiple sexually transmitted infections are significant causes of infertility, PID, ectopic pregnancy, congenital infections and cancer. Morbidity, mortality and long-term complications of these infections are increasing public health concerns worldwide [1, 14, 17, 18, 25-30]. Several studies have reported that the frequency of SNPs is different in communities and races; for instance, MTHFR 677 TT, CC and CT genotype frequencies in the following populations are as follows: East Asians, India, Mexico, Poland and Netherlands [29-33]. In our study, $\mathrm{CC}=27$, $\mathrm{CT}=11$ and $\mathrm{TT}=0$ were calculated for MTHFR C677T, which are nearly similar to this study such as East Asians, Germany, Poland and India [33], and some of the published articles are not similar to this result which are obtained from the USA, China and Denmark [16, 30-32].

The MTHFR A1298C allele frequency was also appraised in Korea, China and India [33]. In the present study, $\mathrm{AA}=14, \mathrm{AC}=8$ and $\mathrm{CC}=6$ were distinguished for the MTHFR A1298C polymorphism, which is similar to the results from India, Korea and China [33] and is in accordance with a Romanian research [10].

The allele's frequencies can have significant relationship with cervical cancer and genital disorders such as Iran [34], China [16], India and Korea [33]. In some cases, results demonstrated an insignificant correlation between the SNPs and women malignancies. The relevance between MTHFR A1298C and C677T in women suffering from cervical intraepithelial neoplasia and genital infections was significant in MTHFR 1298 CC subjects. The high-risk and lowrisk HPV genotypes together with C. tarchomatis, HSV2 and $M$. genitalium were prevalent in cervical intraepithelial neoplasia patients and healthy women (non-cancerous/ non-HPV).

\section{Conclusion}

This can be the first study to investigate the association between MTHFR $1298 \mathrm{~A}>\mathrm{C}$ and $677 \mathrm{C}>\mathrm{T}$ in Iranian women suffering from genital disorders. We concluded that some of SNPs were associated with cervical intraepithelial neoplasia related to HPVs and other STI pathogens. We suggest that studies with larger sample size, different $e$ thnic groups and use of approved and modern technologies such as whole-genome sequencing are needed to confirm the association between mutations and STIs. Finding a specific molecular biomarker can be helpful in detecting early stage 
of genital cancers along with diagnosis of sexually transmitted infections.

Acknowledgement Open access funding provided by Karolinska Institute. We are grateful and indebted to Ms. Fatemeh Eskandari, Faranak Kharazi and Monireh Babaei for their cooperation.

\section{Compliance with Ethical Standards}

Conflict of interest The authors declare that there is no conflict of interest.

Ethics Standard All procedures followed were in accordance with the ethical standards of the responsible committee on human experimentation (institutional and national) and with the Helsinki Declaration of 1975 , as revised in 2008

Informed Consent Informed consent was obtained from all patients for being included in the study.

Open Access This article is licensed under a Creative Commons Attribution 4.0 International License, which permits use, sharing, adaptation, distribution and reproduction in any medium or format, as long as you give appropriate credit to the original author(s) and the source, provide a link to the Creative Commons licence, and indicate if changes were made. The images or other third party material in this article are included in the article's Creative Commons licence, unless indicated otherwise in a credit line to the material. If material is not included in the article's Creative Commons licence and your intended use is not permitted by statutory regulation or exceeds the permitted use, you will need to obtain permission directly from the copyright holder. To view a copy of this licence, visit http://creativecommons.org/licenses/by/4.0/.

\section{References}

1. Mongelos P, Mendoza LP, Rodriguez-Riveros I, et al. Distribution of human papillomavirus (HPV) genotypes and bacterial vaginosis presence in cervical samples from Paraguayan indigenous. Int J Infect Dis. 2015;39:44-9.

2. Sohrabi A, Mirab-Samiee S, Modarresi MH, et al. Development of in-house multiplex real time PCR for human papillomavirus genotyping in Iranian women with cervical cancer and cervical intraepithelial neoplasia. Asian Pac J Cancer Prev. 2014;15(15):6257-61.

3. Sohrabi A, Mirab-Samiee S, Rahnamaye-Farzami M, et al. C13orf18 and C1orf166 (MULAN) DNA genes methylation are not associated with cervical cancer and precancerous lesions of human papillomavirus genotypes in Iranian women. Asian Pac J Cancer Prev. 2014;15(16):6745-8.

4. Agodi A, Barchitta M, Cipresso R, et al. Distribution of p53, GST, and MTHFR polymorphisms and risk of cervical intraepithelial lesions in sicily. Int J Gynecol Cancer. 2014;20(1):141-6.

5. Angchaisuksiri P. Cancer-associated thrombosis in Asia. Thromb J. 2016;14(Suppl 1):26.

6. González-Herrera L, Rodríguez-Morales P, Gonza Lez-Losa Mdel $\mathrm{R}$, et al. MTHFR/p53 polymorphisms as genetic factors for cervical intraepithelial neoplasia and cervical cancer in HPV-infected Mexican women. Int J Biol Markers. 2014;29(2):e142-9.

7. Zhuo WL, Zhang L, Ling JJ, et al. MTHFR C677T and A1298C polymorphisms and cervical carcinoma susceptibility: meta-analyses based on 4421 individuals. Mol Biol Rep. 2012;39(9):8723-32.

8. Long S, Yang X, Liu X, et al. Methylenetetrahydrofolate reductase (MTHFR) polymorphisms and susceptibility for cervical lesions: a meta-analysis. PLoS ONE. 2012;7(12):e52381.

9. Liew SC, Gupta ED. Methylenetetrahydrofolate reductase (MTHFR) C677T polymorphism: epidemiology, metabolism and the associated diseases. Eur J Med Genet. 2015;58(1):1-10.

10. Botezatu A, Socolov D, Iancu IV, et al. Methylenetetrahydrofolate reductase (MTHFR) polymorphisms and promoter methylation in cervical oncogenic lesions and cancer. J Cell Mol Med. 2013;17(4):543-9.

11. Prasad VV, Wilkhoo H. Association of the functional polymorphism C677T in the methylenetetrahydrofolate reductase gene with colorectal, thyroid, breast, ovarian, and cervical cancers. Onkologie. 2011;34(8-9):422-6.

12. Eskandari F, Akbari MT, Karizi SZ. Association of C677T and A1298C polymorphisms of the MTHFR gene with recurrent pregnancy loss. Pajoohande. 2013;18(4):167-73.

13. Abdolmaleki M, Sohrabi A. Characterization of JAK2 V617F $(1849 \mathrm{G}>\mathrm{T})$ mutation in Cervical Cancer related to human papillomavirus and sexually transmitted infections. J Cancer Prev. 2018;23(2):82-6.

14. Moharreri M, Sohrabi A. Herpes simplex virus 2, Mycoplasma genitalium and Chlamydia trachomatis: Are they related to HPV genotypes associated with cervical cancer and genital infections? Infect Disord Drug Targets. 2020;20:1-7.

15. Sohrabi A, Rahnamaye-Farzami M, Mirab-Samiee S, et al. Comparison of in-house multiplex real time PCR, Diagcor GenoFlow HPV array test and INNO-LiPA HPV genotyping extra assays with LCD-array kit for human papillomavirus genotyping in cervical liquid based cytology specimens and genital lesions in Tehran, Iran. Clin Lab. 2016;62(4):615-9.

16. Luo YL, Ye P, Zhang QH, et al. Methylenetetrahydrofolate Reductase C677T polymorphism and susceptibility to cervical cancer and cervical intraepithelial neoplasia: a meta-analysis. PLoS ONE. 2012;7(9):e46272.

17. Miyata T, Maruyama K, Banno F, et al. Thrombophilia in East Asian countries: Are there any genetic differences in these countries? Thromb J. 2016;14(Suppl 1):25.

18. Gerhard DS, Nguyen LT, Zhang ZY, et al. A relationship between methylenetetrahydrofolate reductase variants and the development of invasive cervical cancer. Gynecol Oncol. 2003;90(3):560-5.

19. Zhu XL, Liu ZZ, Yan SX, et al. Association between the MTHFR A1298C polymorphism and risk of cancer: evidence from 265 case-control studies. Mol Genet Genom. 2016;291(1):51-63.

20. Shayanfar N, Babaheidarian P, Rahmani H, et al. Epidermodysplasia verruciformis associated with plasmablastic lymphoma and hepatitis B virus infection. Acta Dermatovenerol Croat. 2012;20(4):267-71.

21. Hajia M, Sohrabi A. Possible synergistic interactions among multiple HPV genotypes in women suffering from genital neoplasia. Asian Pac J Cancer Prev. 2018;19(3):785-9.

22. Sohrabi A, Hajia M. Cervical cancer and genital infections: assessment of performance and validation in human papillomavirus genotyping assays in Iran, its neighbouring countries and Persian Gulf area. Iran J Pathol. 2017;12(1):35-44.

23. Sohrabi A, Hajia M, Jamali F, et al. Is incidence of multiple HPV genotypes rising in genital infections? J Infect Public Health. 2017;10(6):730-3.

24. Golshekan E, Sohrabi A. The point mutation analysis of Cyp2C $9^{* 2}$ (Arg144Cys C > T), Cyp2C9 ${ }^{* 3}$ (Ile359Leu A $>$ C) and VKORC1 $(1639 \mathrm{G}>\mathrm{A})$ in women with cervical cancer related to HPV: a case-control study. J Cell Physiol. 2020. https://doi. org/10.1002/jcp.29731. 
25. D'Amico M, Pasta F, Pasta L. Thrombophilic genetic factors PAI-1 4G-4G and MTHFR 677TT as risk factors of alcohol, cryptogenic liver cirrhosis and portal vein thrombosis, in a Caucasian population. Gene. 2015;568(1):85-8.

26. Simone B, De Stefano V, Leoncini E, et al. Risk of venous thromboembolism associated with single and combined effects of Factor V Leiden, Prothrombin 20210A and Methylenetethraydrofolate reductase C677T: a meta-analysis involving over 11,000 cases and 21,000 controls. Eur J Epidemiol. 2013;28(8):621-47.

27. Farajzadeh M, Bargahi N, Poursadegh Zonouzi A, et al. Polymorphisms in thrombophilic genes are associated with deep venous thromboembolism in an Iranian population. Meta Gene. 2014;2:505-13.

28. Zamani S, Sohrabi A, Rahnamaye-Farzami M, et al. Glutathione S-transferase omega gene polymorphism as biomarker for human papilloma virus and cervical cancer in Iranian women. J Turk Ger Gynecol Assoc. 2018;19(4):193-200.

29. Mei Q, Zhou D, Gao J, et al. The association between MTHFR 677C $>$ T polymorphism and cervical cancer: evidence from a meta-analysis. BMC Cancer. 2012;12:467.

30. Zacho J, Yazdanyar S, Bojesen SE, et al. Hyperhomocysteinemia, methylenetetrahydrofolate reductase $\mathrm{c} .677 \mathrm{C}>\mathrm{T}$ polymorphism and risk of cancer: cross-sectional and prospective studies and meta-analyses of 75,000 cases and 93,000 controls. Int J Cancer. 2011;128(3):644-52.

31. Guo LN. Methylenetetrahydrofolate reductase C677T polymorphism and cervical cancer risk: a meta-analysis. Asian Pac J Cancer Prev. 2012;13(5):2193-7.

32. Goodman MT, McDuffie K, Hernandez B, et al. Association of methylenetetrahydrofolate reductase polymorphism C677T and dietary folate with the risk of cervical dysplasia. Cancer Epidemiol Biomarkers Prev. 2001;10(12):1275-80.
33. Yi K, Yang L, Lan Z, Xi M. The association between MTHFR polymorphisms and cervical cancer risk: a system review and meta-analysis. Arch Gynecol Obstet. 2016;294(3):579-88.

34. Hajiesmaeil M, Tafvizi F, Sarmadi S. The effect of methylenetetrahydrofolate reductase polymorphisms on susceptibility to human papilloma virus infection and cervical cancer. Infect Genet Evol. 2016;46:1-6.

Publisher's Note Springer Nature remains neutral with regard to jurisdictional claims in published maps and institutional affiliations.

\section{About the Author}

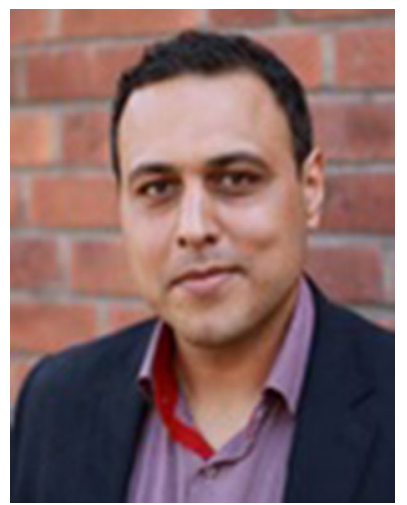

Dr. Amir Sohrabi is working as a Postdoc/Senior Researcher Specialist and Lab Manager in the Department of Medical Epidemiology and Biostatistics, Karolinska Institute, Stockholm, Sweden. He graduated in Molecular Medicine (Ph.D.) from Tehran University of Medical Sciences, Iran. He has special interest in the microbiome of gastrointestinal and genital cancers and mutation profiling. 